\title{
Socioloog en kritisch katholiek
}

\section{In memoriam Leonardus (Bert) Laeyendecker (1930 - 2020)}

\author{
Herman Noordegraaf \& Kees de Groot*
}

L. Laeyendecker was een grootheid in de Nederlandse sociologie en in de beweging van kritische katholieken. Kenner van het werk van Niklas Luhmann èn behoedzaam strijder tegen onbezonnen vooruitgangsgeloof in de maatschappij en restauratieve tendensen in de Rooms-Katholieke Kerk. Hij was zowel voorzitter van de Nederlandse Sociologische Vereniging (1982-1986) als bestuurslid van de Acht Mei Beweging, een los verband van organisaties die elkaar vonden in hun reactie op het omstreden bezoek van paus Johannes Paulus II, op 8 mei 1985, aan de Nederlandse kerkprovincie. Een terugblik op leven en werk van een socioloog die niet ophield vaagheid, dikdoenerij en onzorgvuldigheden te bestrijden. Vlijmscherp en vaak met humor. Zijn leven geeft ook een tijdsbeeld van het kritisch katholicisme vanaf de jaren zestig. Dit artikel bestaat uit twee delen: het eerste bevat een levensschets, in het tweede wordt het wetenschappelijk werk belicht.

\section{Biografie $^{1}$}

Leonardus Laeyendecker werd op 18 juni 1930 in Utrecht geboren als jongste in een gezin dat verder nog twee meisjes telde. Het gezin was 'goed katholiek', maar het was wel het katholicisme van boven de rivieren: niet rigide vasthoudend aan ge- en verboden. Leo groeide op in een arbeidersgezin (zijn vader was boekbinder in een katholiek grafisch bedrijf) dat het onder meer door de crisistijd niet breed had. Omdat Leo een goede leerling was, adviseerde de school om hem niet door te sturen naar het beroepsonderwijs, maar te laten doorleren. Daarop ging Leo naar het St. Bonifacius Lyceum. Inmiddels was het oorlogstijd. In het laatste oorlogsjaar (hongerwinter!) werd hij ondergebracht in een katholiek boerengezin in de Achterhoek. Na de bevrijding keerde hij terug in Utrecht om daar zijn school af te maken.

* Herman Noordegraaf is emeritus hoogleraar voor diaconaat aan de Protestantse Theologische Universiteit. Hij werkte o.a. met Bert Laeyendecker samen in het kader van het Multidisciplinair Centrum voor Kerk en Samenleving (MCKS). Kees de Groot is KSGV hoogleraar sociologie van levensbeschouwing en geestelijke volksgezondheid aan Tilburg University en lid van de redactie van Religie Q Samenleving. 
Na zijn eindexamen in 1948 was hij kort werkzaam op een bank om daarna toe te treden tot de in Utrecht actieve orde van de Augustijnen. Dat leven trok hem aan: veel bezinning en studie en bekend om de onderlinge gemeenschapszin. Hij nam de ordenaam aan van Bertrandus, al gauw gewoon Bert. Zo werd hij voortaan genoemd. Vanaf 1950 studeerde hij theologie en filosofie bij de Augustijnen en maakte hij grondig kennis met het werk van Augustinus. In 1957 werd hij tot priester gewijd: L. Laeyendecker O.S.A. De studieleiding van de orde wees hem aan om verder te studeren in de sociografie om daarna leraar aardrijkskunde te worden aan een van de scholen van de Augustijnen. Maar zijn belangstelling was breder. Daarom ging hij in 1958 sociografie studeren aan wat toen nog heette de Gemeente Universiteit van Amsterdam (GU), waar hij ook veel sociologie erbij kon nemen (Laeyendecker 1998). Hij was een van de oudere studenten en liep bovendien nog met boordje. Hij ging niet in een klooster wonen, maar in de pastorie van een parochie in Amsterdam-West waar hij ook pastoraal werk verrichtte. Naast het hoofdvak sociografie deed hij de bijvakken sociologie en godsdienstsociologie. Toen hij in 1964 zijn doctoraal examen cum laude had afgelegd, werd hij wetenschappelijk medewerker bij de hoogleraar sociologie Sjoerd Hofstra. In 1967 promoveerde hij bij hem op het proefschrift Religie en conflict. De zogenaamde sekten in sociologisch perspectief.

Het was de tijd van het Tweede Vaticaans Concilie, waarin de vragen van kerkvernieuwing en het bij de tijd brengen van de kerk volop aan de orde waren. Laeyendecker voelde zich sterk betrokken bij dit vernieuwingsstreven. Zo droeg hij actief bij aan het Pastoraal Concilie, dat ingesteld door de Bisschoppenconferentie de vernieuwingsbesluiten in de Nederlandse kerkprovincie wilde invoeren. Toen het tij keerde, ontwikkelde hij zich verder als 'kritisch katholiek', die zich met anderen inzette om de kerk bij de tijd te brengen en een dialogisch leergezag voorstond. Vanuit die achtergrond nam hij actief deel aan vernieuwingsbewegingen, zoals de Landelijke Beweging Open Kerk (die ontstond na de benoeming van de conservatieve bisschop Gijsen in Roermond in 1972), waarvan hij voorzitter werd, en later de Acht Mei Beweging (AMB), die bestond van 1985-2003 (Laeyendecker 1995; Van den Beld 2015). Hij was lid van de Studiecommissie van de AMB (1989-1991) en van het algemeen en dagelijks bestuur (1996-2003).

Terug naar zijn academische loopbaan. De volgende stap was zijn benoeming per 1 augustus 1969 tot lector in de sociologie. Eerder in dat jaar was hij uitgetreden uit de orde. Op zondag 19 januari 1969 deelde de pastoor van de Augustinuskerk in Amsterdam-West tijdens de missen vanaf de preekstoel mee dat pater Laeyendecker de orde verliet en het priesterambt neerlegde. ${ }^{2}$ In 
godsdienstsociologische bijeenkomsten had hij namelijk een vakgenote in de godsdienstsociologie, Mady A. Thung, leren kennen en later met haar samengewerkt in de redactie van een boekenreeks Terzake waarin sociologen en theologen in gesprek gingen over allerlei thema's op het terrein van de kerkvernieuwing. ${ }^{3}$ Het werd een relatie, die vanwege zijn priesterschap twee jaar lang diep geheim moest blijven totdat zij in 1969 tot een huwelijk besloten.

Een volgende stap in zijn universitaire loopbaan was zijn hoogleraarschap algemene sociologie aan de Rijksuniversiteit Leiden. Als zodanig is hij van 1973 tot 1989 werkzaam geweest op het Sociologisch Instituut te Leiden. Hij was een begenadigde docent die met een krachtige stem glashelder college gaf. Hij stelde hoge eisen aan de studenten en werd soms wel als afstandelijk ervaren; voor tentamens bij hem was men meestal bang. In deze jaren publiceerde hij belangrijk werk. Zijn betekenis als socioloog werd erkend door de benoeming als lid van de Koninklijke Nederlandse Academie van Wetenschappen in 1979.

Van 1981 tot 1983 was hij decaan van de faculteit sociale wetenschappen. Dat was geen eenvoudige en prettige functie omdat het een tijd van reorganisatie (lees: bezuinigingen) was. Als klap op de vuurpijl besloot de minister van Onderwijs en Wetenschappen W. Deetman na doorvoering daarvan alsnog om het Sociologisch Instituut op te heffen. Hierop legde Laeyendecker zijn ambt neer, niet omdat de sluiting als zodanig hem daartoe noopte - hij werd uitgenodigd om naar de Erasmus Universiteit Rotterdam te komen maar omdat het universitaire klimaat het werken steeds onaantrekkelijker maakte. De nieuwe zakelijkheid, de ondernemende universiteit, de disciplinering van de onderzoekers, de uitholling van de autonomie en van de kritische functie van de universiteit stonden hem tegen. En dat liet hij blijken in zijn afscheidscollege (24 februari 1989) over de ontgrenzing van de nieuwsgierigheid (Laeyendecker 1989; idem 1994, 80-94).

$\mathrm{Na}$ zijn vervroegde emeritering werd hij onbezoldigd directeur van het Multidisciplinair Centrum voor Kerk en Samenleving (MCKS) in Driebergen. ${ }^{4}$ Dit was een centrum van studie en beraad ten dienste van kerken en oecumene met het oog op hun bijdrage aan een rechtvaardige en duurzame samenleving. Het was in 1981 opgericht door Mady A. Thung en de in de oecumene actieve econoom H.M. (Harry) de Lange, en heeft als werkorganisatie tot 1998 bestaan. Het directeurschap duurde relatief kort. In 1991 kreeg Laeyendecker een hartinfarct (en in 2005 volgde nog een zware operatie). Hij werd genoodzaakt een ander leven te gaan leiden, strikt gebonden aan bepaalde leefregels. Toch bleef hij publicistisch actief. Daarnaast besteedde hij tijd aan zijn 
hobby's: fotografie, klassieke muziek en het lezen van literatuur en detectives. Het is een wonder dat hij nog bijna dertig jaar geleefd heeft.

In zijn laatste levensperiode woonden Laeyendecker en zijn vrouw in het Sticht, eerst in Bunnik, vervolgens in Doorn en ten slotte in Driebergen. Hij is altijd katholiek gebleven, al betrof dat niet het katholicisme van Rome na de restauratie die volgde op het Tweede Vaticaans Concilie. De protestantse wereld was hem ook bekend, uit studie en contacten, en dat werd versterkt door zijn protestantse vrouw. Zij bezochten samen in deze levensperiode de diensten van de oecumenische studentengemeente EUG in de Janskerk in Utrecht en na hun verhuizing de zondagse bijeenkomsten van de vrijzinnig protestantse (oorspronkelijk Nederlandse Protestantenbond, NPB) Parklaankerk in Driebergen, een open en ondogmatische gemeenschap waarin zij zich goed thuis voelden. Hij ging er voor hun verhuizing ook regelmatig voor in diensten, evenals in andere NPB-kerken in den lande. Ondanks zijn hartkwaal, kon hij nog zijn negentigste verjaardag vieren. Korte tijd daarna werd hij ziek, waarna hij op 8 augustus 2020 overleed.

Het slotlied in de uitvaartdienst op 15 augustus 2020 in Doorn was het lied 'De steppe zal bloeien', een lied van Huub Oosterhuis en ooit uitgeroepen tot het mooiste religieuze lied. Het was het lijflied van de Acht Mei Beweging en ook van Bert Laeyendecker. Het is een lied vol bijbelse beelden waarin joden hun geschiedenis interpreteren als een verbond met God die altijd uitzicht op redding geeft. Het is ook een lied dat verwijst naar de redding door de opstanding. Laeyendecker was overtuigd van een leven na dit leven, van wat godsdienstsociologen een buitenempirische werkelijkheid noemen, waarin alles wat krom is rechtgezet zal worden en recht gedaan wordt aan de slachtoffers van de geschiedenis. Tevoren had hij als tekst op zijn rouwkaart Apocalyps 21: 3-4 gekozen: 'En Hij, God met hen, zal hun God zijn. Hij zal alle tranen wegwissen uit hun ogen en de dood zal niet meer bestaan, geen rouw, geen geween, geen smart, want al het oude is voorbij.'

\section{Wetenschappelijk werk}

Het wetenschappelijke werk van Bert Laeyendecker bestrijkt zestig jaren (Köbben 2000). In 1961 publiceerde hij zijn eerste artikel in een tijdschrift. Het droeg de titel 'Onkerkelijkheid' en verscheen in Moeder van Goeden Raad, een maandschrift voor christelijke gezinnen. Het laatste artikel is een boekbespreking van Geloven in het ideaal, door Maarten van den Bos, waarin de 
theoloog en socioloog Willem Banning een centrale rol vervult (Laeyendecker 2020).

In zijn wetenschappelijk werk zijn drie hoofdlijnen te vinden, die overigens op elkaar inwerkten en elkaar bevruchtten: de godsdienstsocioloog, de algemeen socioloog en de kritische analyticus.

\section{De godsdienstsocioloog}

Laeyendecker begon met publiceren in de tijd van het Tweede Vaticaans Concilie, waarbij hij zeer betrokken was. Met zijn godsdienstsociologische publicaties wilde hij bijdragen aan kerkvernieuwing en het bij de tijd brengen van de kerk. In dat kader vroeg hij aandacht voor bevorderende en belemmerende sociologische factoren. Hij wees daarbij op machtsfactoren achter incidenten rond priesters die spreek- en schrijfverboden kregen opgelegd of uit het ambt werden ontheven.

In een aantal boeken en vele artikelen heeft hij zijn inzichten naar voren gebracht. In zijn proefschrift Religie en conflict uit 1967 rekende hij op empirische en theoretische gronden af met het vooringenomen begrip sekte. Vanuit de gevestigde orde wordt het afwijkende beladen met vooroordelen over sociale afkomst en mentale oriëntaties die lang niet altijd correct zijn. (Later werd dit inzicht gehonoreerd in de alternatieve term 'nieuwe religieuze beweging’). Sekten waren volgens Laeyendecker groeperingen van religieus en maatschappelijk onterfden die reële tekortkomingen van de kerk aan de orde stelden. De conflicten die hierdoor ontstonden, konden belangrijke motoren van verandering zijn. Veel sociologische theorieën, waaronder het functionalisme, schoten tekort in hun verklaringen doordat ze eenheid, harmonie en evenwicht centraal stellen. Daardoor werd de eigen betekenis van spanningen en conflicten onderschat. Laeyendecker sloot hier aan bij de conflictsociologie van Ralf Dahrendorf. De blijvende aandacht voor de interactie tussen belangen, die veelal ongelijk zijn, en ideeën is hier al zichtbaar.

In dezelfde periode blies hij, met Pieter H. Vrijhof en D.Th. (Dirk) Kuiper, de Werkgroep Godsdienstsociologie van de Nederlandse Sociologische Vereniging nieuw leven in. In 2014 werd Laeyendecker erelid van de werkgroep. Met Karel Dobbelaere verzorgde hij een bloemlezing van de sociologie van de religie (Dobbelaere \& Laeyendecker 1974). Hij nam zitting in het bestuur van de International Conference for the Sociology of Religion en werd een geziene figuur binnen de internationale wereld van de godsdienstsociologie. In dat kader kunnen we ook zijn voorzitterschap van de werkgroep verstaan die de nieuwe religiositeit onderzocht. Het verslag werd uiteindelijk door Mady Thung verzorgd (Thung 1985). 
In de jaren tachtig neemt hij het onderwerp civil religion op, waarbij hij zich hoedt voor een voortijdig oordeel of er ooit in de Nederlandse geschiedenis wel een breed gedragen publieke godsdienst is geweest. Op niet onaanzienlijke plaatsen werd wel geroepen dat God, Nederland, en Oranje met elkaar verbonden waren, maar nader onderzoek naar de sociale ondersteuning voor dit geloof was geboden (Laeyendecker 1985).

In twee boeken analyseerde hij de Rooms-Katholieke Kerk. Om de beheersing van het charisma is een magistrale Weberiaanse verhandeling over de wording en verwording van het ambtscharisma in de Rooms-Katholieke Kerk. De tragiek van de ontwikkeling staat voorop. Zijn voorkeuren blijken wel, maar staan op de achtergrond (Laeyendecker 1993). Het laatste monopolie van de R.K. Kerk, geschreven als een bijdrage van de Acht Mei Beweging aan de discussie over het ambt, heeft wèl beïnvloeding als inzet. Hier loopt de analyse uit op de conclusie dat het vasthouden aan een priesterambt dat is gereserveerd voor celibataire mannen achterhaald is (Laeyendecker 1999).

Bij de godsdienstsociologische publicaties hoort ook zijn aandacht voor de godsdienstsociologie als sociaal verschijnsel. In Social Compass (Laeyendecker 1984 b) pleitte hij ervoor om de wetenschapssociologie in te zetten om de ontwikkeling van het vak te begrijpen. Er zou gekeken moeten worden naar haar positie tussen maatschappij en academie, naar de eigen geloofsopvattingen van de onderzoeker en naar de rol van de kerk als opdrachtgever van onderzoek. Dertig jaar later was dit thema in dit tijdschrift (RQS) onderwerp van een scherp debat met onderzoeker Chris Dols naar aanleiding van diens proefschrift (2014) over de kerksociologie in Nederland (Laeyendecker 2015a, 2015b; Dols 2015).

Met een existentiële betrokkenheid is hij de ontwikkelingen in het Vaticaan tot op het laatst blijven volgen. Zo verschenen in Civis Mundi twee artikelen waarin hij onder meer inging op het vernieuwingsstreven van paus Franciscus. Aanvankelijk zag hij perspectieven in het optreden van deze paus (Laeyendecker 2016), maar later is hij pessimistischer: de kerk bevindt zich in een ernstige crisis: een existentiële crisis, een geloofscrisis, een structuurcrisis en een leiderschapscrisis (Laeyendecker 2019).

\section{De algemeen socioloog}

In de jaren zeventig ontwikkelde hij zich tot een van de grootste kenners van sociologische theorieën in Nederland. Behalve artikelen en bijdragen aan boeken publiceerde hij een omvangrijke inleiding tot de geschiedenis van de sociologie Orde, verandering, ongelijkheid (Laeyendecker 1981). Dit werk was de neerslag van colleges die hij in 1980 gaf tijdens een half jaar gastdocentschap 
aan de Universitas Indonesia in Jakarta in het kader van een ontwikkelingsproject. Dit leerboek verscheen in 1983 in een Indonesische vertaling. Het bevat niet alleen een overzicht van de ontwikkeling in de theorieën, maar gaat ook in op de historisch-maatschappelijke context en dus op de sociologie als maatschappelijk verschijnsel.

Zijn belangrijkste sociologische publicatie verscheen enige jaren daarna: Sociale verandering. Problemen en theorieën (Laeyendecker 1984a). Het bevat een systematische behandeling van factoren die een rol spelen op het gebied van sociale verandering en van de onderscheiden sociologische perspectieven die gehanteerd worden. Deze worden in hun onderlinge verhoudingen geëvalueerd. Het werd een standaardwerk.

Ook bestuurlijk en redactioneel droeg hij bij aan de ontwikkeling van de sociologie. Zo was hij bestuurslid van de Nederlandse Sociologische Vereniging en redactielid van De Sociologische Gids en van The Netherlands Journal of Sociology.

\section{De kritische analyticus}

Vooral in de tijd van het Multidisciplinair Centrum voor Kerk en Samenleving en daarna heeft Laeyendecker zich beziggehouden met een kritische analyse van de moderne samenleving en haar cultuur (visies op mens en wereld, waarden en normen). Als publicaties zijn onder meer te noemen: Brengt de vooruitgang ons verder? (1986), Bedreigde cultuur. Over moderniteit, wetenschap en religie (1994) en In de houdgreep van de tijd. Onze omgang met de tijd in een consumptieve cultuur (2003). Deze studies kenmerken zich door een historisch-sociologische benadering met een Weberiaanse inslag. Er is aandacht voor de materiële sociaaleconomische verhoudingen en voor de cultuur in de zojuist genoemde betekenis. Materiële belangen drijven het handelen voort, maar ook ideële belangen, want er is een behoefte aan zin die aan ervaringen en het leven kan worden toegekend. Deze werken zich uit in ideeënsystemen of wereldbeelden.

Een voorbeeld daarvan is de idee van de vooruitgang. Het denken in termen van vooruitgang is een kenmerk van de moderniteit en bovendien in een bepaalde zin, namelijk van wetenschappelijk-technische vooruitgang en economische groei. De westerse moderne samenleving wordt gekenmerkt door wetenschap, technologie en economie (WTE). Deze zijn systemen geworden met een eigen doelstelling. Laeyendecker maakt hierbij gebruik van de systeemtheorie van N. Luhmann. Hij behoorde tot de weinigen in Nederland die diens omvangrijke werk - met een uiterst hoog abstractieniveau - tot zich genomen had.5 Luhmann wees op de eigen dynamiek van elk systeem, die 
op de vervulling van de eigen functiespecifieke grondslag is gericht, zoals economische groei voor de economie en vermeerdering van de kennis door de wetenschap. De vraag naar het waartoe, in welk 'perspectief van zin' de ontwikkelingen staan, is daardoor steeds meer op de achtergrond geraakt; er vindt een eliminatie van zin plaats. Cultuur, politiek en maatschappij worden aan de eigen dynamiek van de systemen ondergeschikt gemaakt. Dat leidt tot een vermagering van de cultuur. In termen van Karl Mannheim: de functionele rationaliteit overvleugelt de substantiële rationaliteit. Kenmerkend voor het eerste type rationaliteit is dat de middelen zo effectief en efficiënt mogelijk op de gegeven doeleinden worden afgestemd. Bij het tweede gaat het om het 'zinvolle' geheel waarbinnen winst, nieuwe kennis en technische vooruitgang de hun toekomende plaats hebben (Laeyendecker 1994, 25).

Deze systemen hebben veel verbeteringen bewerkstelligd, zoals vergroting van de materiële welvaart, de gezondheidswinst en vrijheid, maar kennen belangrijke schaduwzijden zoals aantasting van het milieu, armoede, sociale ongelijkheid, hoge eisen van productiviteit en keuzestress. Laeyendecker heeft het WTE-complex in werking gezien tijdens de zeventien jaar (19892006) dat hij lid was van een departementale commissie die tot taak had om de opkomende genetische modificatie van dieren op ethische aanvaardbaarheid te toetsen. Hij behoorde tot de minderheid die een sterk terughoudend goedkeuringsbeleid voorstond (het 'nee' in het 'nee tenzij'). Het overgrote deel van de aanvragen werd echter goedgekeurd mede omdat de meerderheid van de commissie natuurwetenschappers en medici waren die belanghebbend waren bij dit soort onderzoek. Alles werd goedgekeurd als het maar, aldus Laeyendecker, bijdroeg aan de bestrijding van kanker (Laeyendecker 1994, $110-125)^{6}$

In 2013 liet Laeyendecker maatschappijkritische stemmen aan het woord in wat naast Sociale verandering als zijn tweede magnum opus genoemd kan worden: Kritische stemmen. Maatschappijkritiek van Oudheid tot heden (Laeyendecker 2013). Dit boek was de uitwerking van een achttal HOVOcolleges (Hoger Onderwijs voor Ouderen) in Utrecht, die na zeven jaren van noeste arbeid uitgroeiden tot een boek van 800 bladzijden. Trouw betitelde het in een bespreking als 'oerdegelijk naslagwerk over de geschiedenis van de maatschappijkritiek'.7 Maar, zoals ook uit de bespreking blijkt, is het boek meer dan een beschrijvende encyclopedie: ook sociologische achtergronden, analyse en een evaluatie komen aan de orde.

Laeyendecker was pessimistisch over de mogelijkheden om de systemen fundamenteel te veranderen, maar dat mocht geen beletsel zijn om aan verbeteringen te werken. De categorie hoop was voor hem heel wezenlijk 
(Laeyendecker 1986, 160; idem 2018). Niet voor niets eindigt hij Kritische stemmen met een van zijn lievelingscitaten uit het werk van Max Weber:

Men moet '(...) krachtig en geduldig boren in hard hout met hartstocht en innerlijke rust tegelijk. Het is volstrekt juist, het wordt door de historische ervaring bevestigd, dat men ook het mogelijke niet realiseren kan, als niet steeds opnieuw in de wereld het onmogelijke wordt nagestreefd. (...) Ook wie geen leider of held is, dient zich te wapenen met een standvastigheid van hart, die ertegen opgewassen is als alle hoop schipbreuk lijdt. Anders zal hij niet in staat zijn het nu mogelijke te verwezenlijken.' (Laeyendecker 2013, 774).

\section{Noten}

1 We danken dr. Mady A. Thung voor de gegevens die zij ons verstrekte. Zie ook de bijdrage die zij schreef voor het liber amicorum dat Laeyendecker kreeg aangeboden t.g.v. zijn zeventigste verjaardag (Thung 2000).

2 De Volkskrant, 20 januari 1969, De Tijd, 21 januari 1969.

3 Zie de vier bundels die verschenen van 1967-1969 bij Ambo/Utrecht en Bosch \& Keuning/Baarn. De redactie was interconfessioneel samengesteld en ook de auteurs van artikelen hadden onderscheiden kerkelijke achtergronden.

4 Voor de geschiedenis van het MCKS zie Herman Noordegraaf \& Greetje Witte-Rang (2011).

5 Reeds in zijn boek Sociale verandering ging Laeyendecker (1984a, 293-314) uitvoerig in op Luhmann. Hij noemt het werk van Parsons concreet in vergelijking met dat van Luhmann.

6 Vgl. Laeyendecker 2018, waarin hij biotechnologie op grond van zijn lidmaatschap van de commissie als voorbeeld noemt van de autonomie van systemen en subsystemen.

7 Trouw, 30 oktober 2013 .

\section{Literatuur}

Beld, Tom van den (2015),

Het andere gezicht van de kerk. De Acht Mei Beweging 1985-2003, Nijmegen: Valkhof Pers.

Dobbelaere, K \& L. Laeyendecker (red.) (1974),

Godsdienstsociologie, kerk en samenleving. Godsdienstsociologische opstellen, Rotterdam:

Universitaire Pers/Antwerpen: Standaard Wetenschappelijke Uitgeverij.

Dols, Chris (2014),

Fact Factory: Sociological Expertise and Episcopal Decision Making in the Netherlands, 1946-1972, Nijmegen: Radboud Universiteit. 
Dols, Chris (2015),

Getallen vertaald. Observaties ter verheldering van het sociologiseringsdebat in de recentere historiografie van het Nederlands katholicisme, in: Religie \& Samenleving $10(3), 235-249$.

Köbben, André e.a. (red.) (2000),

Homo prudens. Religie, cultuur en wetenschap in de moderne samenleving, Leende: Damon, 2000.

Laeyendecker, L. (1967),

Religie en conflict. De zogenaamde sekten in sociologisch perspectief, Meppel: Boom.

Laeyendecker, L. (1981),

Orde, verandering, ongelijkheid. Een inleiding tot de geschiedenis van de sociologie, Amsterdam: Boom.

Laeyendecker, L. (1984a),

Sociale verandering. Problemen en theorieën, Amsterdam: Boom.

Laeyendecker, L. (1984b),

The sociology of religion: deficiencies and opportunities, in: Social Compass, 31 (2/3), 157-167.

Laeyendecker, (1985),

Publieke godsdienst en macht, in: Laeyendecker, L. \& O. Schreuder (red.) (1985),

Religie en politiek. Verkenning op een spanningsveld, Kampen: Kok Agora, 131-156.

Laeyendecker, L. (1986),

Brengt de vooruitgang ons verder? Kanttekeningen bij een wijd verbreid geloof, Baarn:

Ten Have.

Laeyendecker, L. (1989),

De zuilen van Hercules voorbij, in: Adriaansens, H.P.M. (red.), Zinproblemen in de moderne cultuur; afscheidsbundel aangeboden aan prof. dr. Bert Laeyendecker, Culemborg: Lemma, 55-84.

Laeyendecker, L. (1993),

Om de beheersing van het charisma. Heil en macht in de R.K. Kerk, Amsterdam enz.: Verhandelingen der Koninklijke Akademie van Wetenschappen, Afd. Letterkunde, Nieuwe Reeks, deel 157.

Laeyendecker, L. (1994),

Bedreigde cultuur. Over moderniteit, wetenschap en religie, Kampen: Kok.

Laeyendecker, L. (1995),

De Acht Mei beweging: postmoderne uitdaging aan de kerk, in: Kranenborg, R. (red.), Rooms Katholieken, Amsterdam: VU Uitgeverij, 1-41. 
Laeyendecker, L. (1998),

S. Hofstra. Bedachtzaam en zijn tijd vooruit, in: Goudsblom, J. e.a. (red.), In de zevende.

De eerste lichting hoogleraren aan de Politieke Sociale Faculteit Amsterdam, Amsterdam:

Het Spinhuis, 82-95.

Laeyendecker, L. (1999),

Het laatste monopolie van de R.K. Kerk. Veranderende verhoudingen tussen priesters en leken, Gorinchem: Narratio.

Laeyendecker, L. \& Marthy P. Veerman (2003),

In de houdgreep van de tijd. Onze omgang met de tijd in een consumptieve cultuur, Budel:

Damon.

Laeyendecker, L. (2013),

Kritische stemmen. Maatschappijkritiek van oudheid tot heden, Budel: Damon.

Laeyendecker (2015a),

Sociologen en bisschoppelijk beleid. Kritische overwegingen bij de dissertatie van

Chris Dols, Fact Factory: Sociological Expertise and Episcopal Decision Making in the

Netherlands, 1946-1972, in: Religie \& Samenleving, 10 (1), 44-62.

Laeyendecker (2015b),

Dupliek: Geringe kritiektolerantie, in: Religie \& Samenleving, 10 (3), 250-259.

Laeyendecker, L. (2016),

Conflicten in het Vaticaan, in: Civis Mundi, 20 november 2016. Geraadpleegd op https://www.civismundi.nl/?p=artikel\&aid=3161.

Laeyendecker, L. (2018),

Systemen in de beklaagdenbank: zijn ze nog te veranderen?, in: Civis Mundi, 5 mei 2018. Geraadpleegd op https://www.civismundi.nl/?p=artikel\&aid=3959.

Laeyendecker, L. (2019),

De r.k. kerk opnieuw in zwaar weer geraakt. Is zij vergelijkbaar met de situatie in de ${ }_{16} 6^{\mathrm{e}}$ eeuw, die uitliep op de reformatie?, in: Civis Mundi, 16 juni 2019.Geraadpleegd op https://www.civismundi.nl/?p=artikel\&aid=5256.

Laeyendecker, L. (2020),

Maarten van den Bos, Geloven in het ideaal. Geschiedenis en actualiteit van de Arbeiders Gemeenschap der Woodbrookers (boekbespreking), in: Religie a Samenleving, 15 (2), 170-173.

Noordegraaf, Herman \& Greetje Witte-Rang (2011),

In de wereld werkzaam zijn. Anders denken over kerkelijk optreden door het MCKS 19811998, Vught: Skandalon. 
Thung, Mady A. (in cooperation with L. Laeyendecker [et al.]) (1985),

Exploring the new religious consciousness. An investigation of religious change, Amsterdam: Free University Press.

Thung, Mady A. (2000),

Met hart en ziel. Socioloog én katholiek. Bevooroordeelde biografische notities, in: Köbben, André e.a., Homo Prudens. Religie, cultuur en wetenschap in de moderne samenleving, Leende: Damon, 210-225. 